\title{
Fatty acid characteristics in two symbiotic gastropods from a deep hydrothermal vent of the West Pacific
}

\author{
V. Pranal ${ }^{1}$, A. Fiala-Médioni ${ }^{1, *}$, J. Guezennec ${ }^{2}$ \\ 'Observatoire Océanologique, laboratoire ARAGO, Université Pierre et Marie Curie-CNRS URA 117, BP 44, \\ F-66651 Banyuls-sur-mer cedex, France \\ ${ }^{2}$ IFREMER centre de Brest, DRO/EP/LBMH, BP 70, F-29280 Plouzané, France
}

\begin{abstract}
Two deep-sea gastropods, Ifremeria nautilei and Alviniconcha hessleri, collected on a hydrothermal site of the North Fiji Basin (Southwestern Pacific) were analysed for polar and neutral lipids using gas-liquid chromatography/mass spectrometry. A high level of monounsaturated fatty acids (MUFAs) and a low level of 103 series polyunsaturated fatty acids (PUFAs) indicated that nutrition of both gastropods was related to a food web based mainly on bacterial supply. From differences in MUFA distribution between the 2 gastropods, it appeared that most of the energy requirements of $A$. hessleri were supplied by sulfur-oxidizing endobacteria whereas 1 . nautilei probably had a mixotrophic diet based on endogenous as well as exogenous bacteria. Given the relatively high level of linoleic acid, which represented from 2 to $8 \%$ of the phospholipid fatty acids, hydrothermal gastropods did not appear to be depleted in $\omega 6$ PUFAs. It was hypothesized that they obtain linoleic acid from a pathway different to that in heterotrophic marine molluscs. In contrast to $\omega 6$ PUFAs, both hydrothermal gastropods appeared to be depleted in $\omega 3$ PUFAs, indicating the limited importance of photosynthesisbased food supplies. Some non-methylene-interrupted dienes, particularly 20:209,15 which represented from 9 to $18 \%$ of the phospholipid fatty acids, may be synthesized by deep-sea symbiotic molluscs in order to restore the depleted (1)3 PUFAs considered as essential for animals. Gills of both gastropods had high levels of neutral lipids, mainly MUFAs that may have originated from degradation of endobacterial phospholipids
\end{abstract}

KEY WORDS: Hydrothermal vents - Gastropods Chemosynthetic bacteria - Biomarkers - Fatty acids Phospholipids · Neutral lipids

\section{INTRODUCTION}

Communities associated with deep hydrothermal vents from the East Pacific are usually dominated, in terms of biomass, by a small number of invertebrates belonging to 2 main taxa, namely vestimentiferan tubeworms and bivalve molluscs (Hessler \& Smithey 1983, Tunnicliffe 1991, Childress \& Fisher 1992). The recently discovered hydrothermal vents situated on spreading axes of back-arc basins in the Western

-Addressee for correspondence.

E-mail: afiala@oob-arago.univ-perp.fr
Pacific display radically different biological assemblages that are characterized by the dominance of gastropods as primary consumers (Jollivet et al. 1989, Bouchet \& Waren 1991, Waren \& Bouchet 1993). In particular, 2 large species belonging to the family Provannidae, Alviniconcha hessleri (Okutani \& Ohta 1988) and Ifremeria nautilei (Bouchet \& Waren 1991), closely associated with the fluid emissions, compose most of the vent biomass (Bouchet \& Waren 1991, Galkin 1992, Desbruyères et al. 1994). Electron microscopic and enzymatic studies have shown that these provannid gastropods harbour chemoautotrophic bacteria in specialized gill cells (Stein et al. 1988, Endow \& 
Ohta 1989, Galkin 1992, Desbruyères et al. 1994). The symbionts appear to be sulfur-oxidizing Gram-negative bacteria but another type, probably related to nitrifying or methylotroph bacteria, may coexist in the same vacuoles (Endow \& Ohta 1989, Galkin 1992). A. hessleri and $I$. nautilei are the only gastropods presently known to be associated with chemosynthetic endobacteria and their ecological status, particularly with respect to their nutritional strategy, and specific metabolic characteristics are little known. Although their radula and gut are reduced, their stomach contains mineral and animal fragments. This suggests that they have a mixotrophic diet supported both by endobacterial carbon transfer and grazing (Stein et al. 1988, Bouchet \& Waren 1991, Desbruyères et al. 1994)

Bivalve molluscs associated with chemolithoautotrophic bacteria, such as lucinids, solemyids and thyasirids from littoral reduced sediments (Conway \& McDowell Capuzzo 1990, 1991, Conway et al. 1992, Zhukova et al. 1992, Fullarton et al. 1995, Pranal 1995) and mytilids and vesicomyids from deep-sea hydrothermal vents (Ben-Mlih et al. 1992, Pranal 1995, Pranal et al. in press), have been analyzed using fatty acids as biomarkers. These studies helped to characterize the metabolism and the ecology of these associations. We have now applied the same approach to the 2 hydrothermal gastropods, Ifremeria nautilei and Alvinicancha hessleri.

\section{MATERIALS AND METHODS}

Station location and description. Specimens of Ifremeria nautilei and Alviniconcha hesslen were collected at the hydrothermal vent site 'Kayo' (16 $59^{\circ} \mathrm{S}$, $\left.173^{\circ} 43^{\prime} W_{i} 1977 \mathrm{~m}\right)$ in the North Fiji back-arc basin (Southwestern Pacific) during the RV 'Yokosuka' cruise (1991). 'Kayo' is located on a very active vent field lying on a steep slope. A 2 m high chimney stood at its center, emitting transparent fluid with a high temperature $\left(296^{\circ} \mathrm{C}\right)$, strong $\mathrm{H}_{2} \mathrm{~S}$ concentration ( $4.0 \mathrm{mmol} \mathrm{kg} \mathrm{kg}^{-1}$ ) and low $\mathrm{pH}$ of the end member fluids, about 4.7 (Ishibashi et al. 1994). Methane is present at concentrations of $45 \mu \mathrm{mol} \mathrm{kg}^{-1}$ (D. Grimaud pers comm.). Basalts lying on this site are covered by scattered bacterial mats. The biological community is similar, but with more abundant individuals, to that of the 'White Lady' site described in Desbruyères et al. (1994). Gastropods, especially Ifremeria nautilei and Alviniconcha hessleri, are the dominant organisms. The associated fauna comprises essentially symbiotic mussels belonging to the species Bathymodiolus brevior (Von Cosel et al. 1994).

Lipid analysis. For both gastropod species, tissues were analyzed from 3 different specimens collected during the same dive, in the same clump of animals Gills and mantles were dissected immediately after arrival on board. Samples were stored in liquid nitrogen and freeze-dried in the laboratory

Lipid extraction, fatty acid purification, and quantification by capillary gas chromatography (GC) were performed as previously described (Bligh \& Dyer 1959, White et al. 1977). Essentially, a modified Bligh \& Dyer chloroform-methanol lipid extraction was used. Total extractable lipids were fractionated by silicic acid column chromatography. The fatty acid esters linked to the phospholipids and the triglycerides were methylated by acidic methanolysis of the polar and neutral lipid fractions, respectively. The resulting fatty acid methyl esters were purified by thin-layer chromatography before GC analysis. Quantification was based on comparison of peak areas to an internal injection standard (19:0). Tentative peak identifications were based on co-elution on a $50 \mathrm{~m}$ nonpolar fused silica capillary column (CP-Sil-5CB, $0.25 \mathrm{~mm}$ i.d., $0.25 \mu \mathrm{m}$ film thickness; Chrompack, Middelburg, The Netherlands) with standards obtained from either Sulpeco, Inc. (Bellefonte, PA, USA), identified laboratory standards or previously analysed lipid extracts from Mytilus galloprovincialis and Bathymodiolus brevior (Pranal 1995. Pranal et al. in press).

Fatty acid structural verification. Identification of fatty acid methyl esters, position of methyl branching, and degree of unsaturation were verified by $\mathrm{GC} / \mathrm{mass}$ spectrometry (MS) as described previously (Nichols et al. 1989, Guezennec 1991). Monounsaturation position and geometry were chemically determined by using dimethyl disulfide (Aldrich Chemical Co., Inc., Milwaukee, WI, USA) and 1 drop of iodine solution (60 $\mathrm{mg}$ of iodine in $1 \mathrm{ml}$ of diethyl ether). Reactions were performed in $2 \mathrm{ml}$ glass vials sealed with a Teflon-lined septum at $50^{\circ} \mathrm{C}$ for $48 \mathrm{~h}$, cooled, and diluted with $200 \mu \mathrm{l}$ of hexane. The iodine was removed by shaking with $200 \mu \mathrm{l}$ of $5 \% \mathrm{Na}_{2} \mathrm{~S}_{2} \mathrm{O}_{3}$. The upper organic phase was removed, the aqueous phase was washed with $100 \mu l$ of hexane, and the combined hexane fractions were dried under nitrogen gas before GC and GC/MS analysis. Detection of both the omega $(\omega)$ and delta $(\Delta)$ fragments confirmed the original double-bond position of the monounsaturates (Guezennec 1991). Geometry was verified by GC separation of the dimethyl disulfide adducts of identical positional isomers analysed by MS.

Fatty acid nomenclature. Fatty acids are characterized by chain length. Carbon number is followed by a colon, then the number of double bonds. The position of unsaturation is specified from the methyl end $(\omega)$ or from the carboxyl end $(\Delta)$. The prefixes ' $i$ ' and ' $a$ ' refer to iso and anteiso branching, respectively. The suffix ' $x$ ' refers to undetermined number of double bonds 
and the suffixes ' $a$ ', ' $b$ ' and 'd' to undetermined positions of unsaturations.

\section{RESULTS}

\section{Fatty acid composition of polar lipids}

Fatty acid concentrations of the polar lipids (Table 1) were quite similar for both gastropods. Higher concentrations were found in gills (12.9 and $9.7 \mathrm{mg} \mathrm{g}^{-1}$ dry weight for Ifremeria nautilei and Alviniconcha hessleri, respectively). Values in mantles were 3 to 4.5 times less (about $3 \mathrm{mg} \mathrm{g}^{-1}$ dry weight). The preponderant fatty acids in gills and mantles of both species were the saturated fatty acid 16:0, the monounsaturated fatty acids (MUFAs),

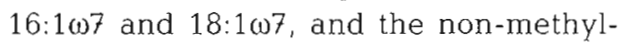
ene-interrupted dienoic (NMID) fatty acid 20:209, 15. Hydrothermal gastropods are characterized by a high level and diversity of MUFAs. In A. hessleri tissues, most of them correspond to even-numbered fatty acids having a double bond in the $\omega 7$ or $\omega 9$ position. The total of these MUFAs represented 49 and $34 \%$ of the fatty acids in gills and in mantles, respectively (Table 2). Despite the high level of $\omega 7$ and $\omega 9$ series MUFAs in I. nautilei tissues ( 26 and $28 \%$ of the total fatty acids in gills and mantles, respectively), this gastropod clearly differed from $A$. hessleri, displaying relatively high levels of even-numbered MUFAs with a double bond in the $\omega 6$ or $\omega 8$ position, which constitute about $7 \%$ of the total fatty acids. This difference was especially pronounced with respect to $\omega 8$ MUFAs, which were exclusively found in $I$. nautilei tissues. Percentages of ramified fatty acids were low, and were lower in $A$. hessleri tissues (less than $0.5 \%$ of the total fatty acids) than in $I$. nautilei tissue (1.2 and $3.1 \%$ of the fatty acids in gills and mantles, respectively). According to the species and the organ, the sum of the polyunsaturated fatty acids (PUFAs) varied from 41 to $43 \%$ of the total fatty acids, except for the gills of $A$. hessleri, in which this sum was much lower ( $27 \%$ of the total fatty acids) PUFAs having a double bond in the $\omega 3$ or $\omega 6$ position composed from $1 / 3$ to $1 / 2$ of the $\sum$ PUFAs and mainly consisted of $18: 2 \omega 6,20: 4 \omega 6,20: 5 \omega 3$ and $22: 5 \omega 3$ for $I$. nautilei, and $18: 2 \omega 6,20: 4 \omega 6$ and $20: 5 \omega 3$ for $A$. hessleri.
Table 1. Fatty acid composition of the polar lipids, as a percentage of total fatty acids, from the symbiotic gastropods Ifremeria nautilei and Alviniconcha hessler collected at the hydrothermal vent site Kayo (North Fiji Basin). Values represent the mean of 3 different animals \pm SD. tr: trace

\begin{tabular}{|c|c|c|c|c|}
\hline \multirow[t]{2}{*}{ Fatty acid } & \multicolumn{2}{|c|}{ Ifremena nautilei } & \multicolumn{2}{|c|}{ Alviniconcha hessleri } \\
\hline & Gills & Mantles & Gills & Mantles \\
\hline $14: 0$ & $0.77 \pm 0.30$ & $1.14 \pm 0.49$ & $0.56 \pm 0.08$ & $1.56 \pm 0.65$ \\
\hline $15: 0$ & $0.05 \pm 0.01$ & $-\quad-$ & $0.19 \pm 0.07$ & $0.14 \pm 0.04$ \\
\hline $16: 0$ & $10.91 \pm 0.66$ & $11.11 \pm 0.98$ & $12.43 \pm 0.80$ & $11.43 \pm 0.38$ \\
\hline $17: 0$ & $0.26 \pm 0.04$ & $0.32 \pm 0.08$ & $0.41 \pm 0.13$ & $0.40 \pm 0.13$ \\
\hline $18: 0$ & $4.20 \pm 0.53$ & $3.77 \pm 0.65$ & $3.31 \pm 0.73$ & $4.30 \pm 1.04$ \\
\hline a $15: 0$ & $0.54 \pm 0.05$ & $-\quad-$ & $-\quad-$ & $-\quad-$ \\
\hline i $17: 0$ & $0.32 \pm 0.17$ & $0.42 \pm 0.06$ & $0.19 \pm 0.21$ & $0.20 \pm 0.03$ \\
\hline a $17: 0$ & $-\quad-$ & $-\quad-$ & $\operatorname{tr}$ & $-\quad-$ \\
\hline i $19: 0$ & $0.19 \pm 0.02$ & $0.36 \pm 0.16$ & $0.27 \pm 0.10$ & - $\quad-$ \\
\hline a $19: 0$ & $0.12 \pm 0.02$ & $1.31 \pm 0.57$ & & $-\quad-$ \\
\hline $16: 105$ & $0.38 \pm 0.17$ & $0.35 \pm 0.14$ & $0.08 \pm 0.03$ & $0.06-$ \\
\hline $16: 1 \omega 6$ & $1.79 \pm 0.46$ & $1.22 \pm 0.30$ & $0.59 \pm 0.25$ & $0.21 \pm 0.07$ \\
\hline $16: 1 \omega 7$ & $4.30 \pm 0.92$ & $4.53 \pm 1.63$ & $19.71 \pm 2.22$ & $8.84 \pm 2.75$ \\
\hline $16: 1 \omega 8$ & $4.12 \pm 1.02$ & $3.31 \pm 0.84$ & $-\quad-$ & $-\quad-$ \\
\hline $17: 1 \omega 6$ & $0.08 \pm 0.02$ & $0.68 \pm 0.08$ & $0.18 \pm 0.08$ & $0.18 \pm 0.02$ \\
\hline $17: 1 \omega 8$ & $0.45 \pm 0.27$ & $-\quad-$ & $-\quad-$ & $-\quad-$ \\
\hline $18: 1 \omega 5$ & $0.13 \pm 0.04$ & $0.11 \pm 0.02$ & $0.11 \pm 0.03$ & $0.06 \pm 0.07$ \\
\hline $18: 1 \omega 6$ & $1.63 \pm 0.35$ & $1.41 \pm 0.18$ & $1.40 \pm 0.51$ & $0.43 \pm 0.07$ \\
\hline $18: 1 \omega 7$ & $11.41 \pm 0.98$ & $12.03 \pm 1.31$ & $17.01 \pm 2.81$ & $11.90 \pm 3.00$ \\
\hline $18: 1 \omega 8$ & $\operatorname{tr}-$ & $1.05 \pm 0.26$ & $-\quad-$ & $-\quad-$ \\
\hline $18: 1 \omega 9$ & $4.81 \pm 0.18$ & $5.86 \pm 0.25$ & $6.12 \pm 1.44$ & $6.00 \pm 1.20$ \\
\hline $19: 1 \omega 8$ & $2.61 \pm 1.91$ & $-\quad-$ & $1.13 \pm 1.34$ & $1.80 \pm 1.64$ \\
\hline $20: 1 \omega 5$ & $0.06-$ & $-\quad-$ & $0.06 \pm 0.02$ & 0.04 \\
\hline $20: 1 \omega 7$ & $1.64 \pm 0.04$ & $1.94 \pm 0.43$ & $1.89 \pm 0.60$ & $1.84 \pm 0.26$ \\
\hline $20: 108$ & $0.07 \pm 0.01$ & $-\quad-$ & $-\quad-$ & $-\quad-$ \\
\hline $20: 1 \omega 9$ & $3.60 \pm 0.42$ & $3.96 \pm 0.50$ & $4.18 \pm 0.47$ & $5.00 \pm 0.92$ \\
\hline $20: 1 \omega 11$ & $3.26 \pm 0.21$ & $3.38 \pm 0.24$ & $3.41 \pm 0.33$ & $5.01 \pm 0.31$ \\
\hline $18: 2 a$ & $1.05 \pm 0.11$ & $0.58 \pm 0.26$ & $0.57 \pm 0.02$ & $0.43 \pm 0.12$ \\
\hline $18: 2 \mathrm{~b}$ & $0.05-$ & $-\quad-$ & $0.27 \pm 0.10$ & $0.10 \pm 0.05$ \\
\hline $18: 2 \omega 6$ & $1.62 \pm 0.56$ & $3.89 \pm 1.73$ & $4.21 \pm 0.99$ & $7.83 \pm 1.42$ \\
\hline $18: 3 \omega 6$ & tr - & $\operatorname{tr}$ & $0.02-$ & $0.03-$ \\
\hline $20: 2 a$ & $1.26 \pm 0.42$ & $1.31 \pm 0.30$ & $1.75 \pm 0.02$ & $0.96 \pm 0.25$ \\
\hline $20: 2 \omega 7,15$ & $3.23 \pm 0.43$ & $2.01 \pm 1.10$ & $1.77 \pm 0.11$ & $1.34 \pm 0.65$ \\
\hline $20: 2 \omega 9,15$ & $18.30 \pm 2.58$ & $13.04+4.79$ & $6.92 \pm 0.91$ & $10.58 \pm 2.09$ \\
\hline $20: 2 d$ & $0.10 \pm 0.01$ & $0.95 \pm 0.25$ & $1.32 \pm 0.53$ & $0.71 \pm 0.37$ \\
\hline $20: 3 a$ & $3.18 \pm 0.58$ & $2.22 \pm 0.63$ & $1.38 \pm 0.31$ & $2.66 \pm 0.31$ \\
\hline $20: 4 \omega 6$ & $6.06 \pm 0.18$ & $3.88 \pm 0.27$ & $4.54 \pm 1.09$ & $5.87 \pm 0.08$ \\
\hline $20: 5 \omega 3$ & $4.31 \pm 0.32$ & $8.08 \pm 3.31$ & $1.87 \pm 0.68$ & $6.87 \pm 1.30$ \\
\hline $21: x$ & $0.83 \pm 0.26$ & $1.09 \pm 0.81$ & $0.79 \pm 0.74$ & $1.54 \pm 0.55$ \\
\hline $22: 2$ a & $0.15 \pm 0.04$ & $-\quad-$ & $0.10 \pm 0.03$ & $0.09 \pm 0.05$ \\
\hline $22: 2 \omega 9,15$ & $0.33 \pm 0.04$ & $-\quad-$ & $0.22 \pm 0.06$ & $0.32 \pm 0.07$ \\
\hline $22: 3 a$ & $0.13 \pm 0.02$ & $\operatorname{tr} \quad-$ & $0.10 \pm 0.02$ & $0.10 \pm 0.01$ \\
\hline $22: 4066$ & $1.00 \pm 0.01$ & $0.66 \pm 0.19$ & $0.45 \pm 0.08$ & $0.61 \pm 0.20$ \\
\hline $22: 5 \omega 3$ & $1.49 \pm 0.09$ & $4.21 \pm 2.00$ & $0.21 \pm 0.09$ & $0.86 \pm 0.28$ \\
\hline $\begin{array}{l}\text { Total, } \\
\mathrm{mg} \mathrm{g}^{-1} \mathrm{~d}\end{array}$ & $12.86 \pm 0.43$ & $2.80 \pm 0.82$ & $9.69 \pm 1.66$ & $3.19 \pm 0.50$ \\
\hline
\end{tabular}

\section{Fatty acid composition of neutral lipids}

Fatty acid concentrations of the neutral lipids (Table 3) are higher in gills (37.5 and $28.8 \mathrm{mg} \mathrm{g}^{-1}$ dry weight for Ifremeria nautilei and Alviniconcha hess- 
Table 2. Relative abundances of different groups of polar and neutral lipid fatty acids, as percentages of total fatty acıds, for the symbiotic gastropods Ifremeria nautilei and Alviniconcha hessleri collected at the hydrothermal vent site Kayo (North Fiji Basin). FA: fatty acid, MUFA: monounsaturated fatty acid; PUFA: polyunsaturated fatty acid, NMID: non-methyleneinterrupted diene

\begin{tabular}{|c|c|c|c|c|}
\hline \multirow[t]{2}{*}{ Fatty acid } & \multicolumn{2}{|c|}{ Ifremeria nautilei } & \multicolumn{2}{|c|}{ Alviniconcha hessler } \\
\hline & Gills & Mantles & Gills & Mantles \\
\hline \multicolumn{5}{|l|}{ Polar lipids } \\
\hline$\sum$ ramified FAs & 1.17 & 3.09 & 0.52 & 0.20 \\
\hline$\sum \omega^{7} \mathrm{MUFAs}^{\mathrm{d}}$ & 17.36 & 18.50 & 38.61 & 22.58 \\
\hline$\sum(\omega 7, \omega 9)$ MUFAs $^{a}$ & 25.77 & 28.32 & 48.91 & 33.59 \\
\hline$\Sigma(\omega 6, \omega 8) \mathrm{MUFAs}^{\mathrm{d}}$ & 7.61 & 7.00 & 1.99 & 0.64 \\
\hline$\sum$ MUFAs & 40.40 & 39.84 & 55.88 & 41.38 \\
\hline$\sum \omega 320,22$ PUFAs & 5.79 & 12.29 & 2.08 & 7.72 \\
\hline$\Sigma(\omega 3, \omega 6) 20,22$ PUFAs & 12.85 & 16.83 & 7.06 & 14.21 \\
\hline$\sum(\omega 3, \omega 6)$ PUFAs & 14.47 & 20.72 & 11.30 & 22.08 \\
\hline$\sum$ NMID FAs & 23.37 & 17.31 & 12.08 & 14.00 \\
\hline$\sum$ PUFAs & 43.09 & 41.91 & 26.53 & 40.94 \\
\hline \multicolumn{5}{|l|}{ Neutral lipids } \\
\hline$\sum$ ramified FAs & 0.26 & 0.35 & 0.36 & 0.77 \\
\hline$\sum \omega 7 \mathrm{MUFAs}^{\circ}$ & 30.22 & 24.63 & 40.74 & 16.98 \\
\hline$\sum\left(\omega^{7}, \omega 9\right)$ MUFAs $^{\circ}$ & 37.31 & 35.51 & 47.99 & 28.76 \\
\hline$\sum_{1}(\omega 6, \omega 8)$ MUFAs $^{3}$ & 25.07 & 17.45 & 2.03 & 0.81 \\
\hline$\sum$ MUFAs & 66.35 & 56.44 & 53.26 & 34.73 \\
\hline$\sum \omega 320,22$ PUFAs & 1.63 & 5.82 & 2.25 & 7.07 \\
\hline$\sum(\omega 3, \omega 6) 20,22$ PUFAs & 4.79 & 9.78 & 7.84 & 15.49 \\
\hline$\Sigma(\omega 3, \omega 6)$ PUFAs & 5.60 & 11.17 & 13.38 & 23.05 \\
\hline$\Sigma$ NMID FAs & 11.21 & 14.74 & 12.41 & 17.89 \\
\hline$\sum$ PUFAs & 19.37 & 30.19 & 28.78 & 47.83 \\
\hline
\end{tabular}

leri, respectively) than in mantles $\left(12.7\right.$ and $7.7 \mathrm{mg} \mathrm{g}^{-1}$ dry weight, respectively). For both organs, concentrations were higher for $I$. nautilei than for $A$. hessleri. Ratios of neutral lipids to polar lipids (NL/PL) in gills were quite similar for both gastropods (ca 3). In mantles, these ratios were high for I. nautilei (4.5) and low for A. hessleri (2.4) The difference between the fatty acid composition of the neutral lipids and that of the polar lipids varied according to the species. In I. nautilei tissues, proportions of the different groups of fatty acids, such as $\Sigma$ branched fatty acids, $\sum$ MUFAs, $\Sigma$ NMID or $\Sigma$ PUFAs, clearly varied between polar and neutral lipids. $\Sigma$ MUFAs increased at the expense of the $\sum$ PUFAs in neutral lipids (Table 2). Particularly, the high levels of $16: 1 \omega 8$ and 18:1 17 fatty acids, especially in gills, should be noted (Table 3 ). In $A$. hessleri tissues, the different groups of fatty acids displayed quite similar levels in polar and neutral lipids (Table 2). However, when the neutral lipid fatty acid composition was examined in detail (Table 3), it could be observed that a strong accumulation of 16:167 occurred in gills (more than a quarter of the neutral lipid fatty acids).

\section{DISCUSSION}

\section{Indices of a food web based mainly on bacterial production}

Analysis of fatty acid composition is a very useful method for studying the trophic sources used by marine organisms. whether heterotrophs (Sargent et al. 1987 1990 ) or invertebrates with symbionts (Conway \& McDowell Capuzzo 1990, BenMlih et al. 1992, Zhukova et al. 1992, Pranal 1995, Pranal et al. in press) The fatty acid composition of Ifreneria nautilei and Alviniconcha hessleri differs greatly from that of other marine gastropods (Ackman et al. 1971, Gardner \& Riley 1972, Ackman \& Hooper 1973, Joseph 1982, Voogt 1983). Both hydrothermal gastropods display large amounts of MUFAs and low amounts of $\omega 3$ series PUFAs, showing that their fatty acid composition more closely resembles that of bacteria than typical marine invertebrates. As has been proposed for worms and bivalves associated with endosymbiotic bacteria (Conway \& McDowell Capuzzo 1990, 1991, Giere et al. 1991, BenMlih et al. 1992, Conway et al. 1992 Zhukova et al. 1992, Fullarton et al. 1995 Pranal 1995, Pranal et al. in press), this fatty acid distribution indicates a nutrition based mainly on bacterial syntheses.

\section{Origin of the microbial markers}

$\omega 7$ and $\omega 9$ series MUFAs constitute almost exclusively the total phospholipid fatty acids of aerobic bacteria (Gurr \& James 1980). Particularly, palmitoleic $\left(16: 1 \omega^{7}\right)$ and vaccenic $\left(18: 1 \omega^{7}\right)$ acids compose most of the fatty acids of free-living sulfur-oxidizing bacteria (McCaffrey et al. 1989, Conway \& McDowell Capuzzo 1990) The preponderance of these 2 markers in Alviniconcha hessleri tissues suggests that its nutrition is based mainly on products synthesized by sulfuroxidizing bacteria. Endosymbionts colonizing the gills probably provide the major contribution. This assumption is supported by (1) the presence of abundant sulfur-oxidizing bacteria in gills, indicated by the high level of palmitoleic and vaccenic acids, significantly higher in the gills (where symbionts live) than in the mantle (devoid of endobacteria), and confirmed by ultrastructural observations and RUBP carboxylase tests (authors' unpubl. results); (2) the weak diversity of the microbial markers which reflects a nutrition 
based on a limited number of trophic sources; and (3) the qualitative and quantitative similarity between these microbial markers and those detected in symbiotic bivalves from deep hydrothermal vents, such as mussels and clams, known to feed mainly through sulfur-oxidizing bacteria inhabiting the gills (Ben-Mlih et al. 1992, Pranal 1995, Pranal et al. in press). The preponderance of endobacterial synthetic products in the nutrition of $A$. hessleri from the North Fiji Basin, suggested here by the fatty acid composition, is consistent with data obtained on Mariana, Manus and Lau back-arc basin specimens which indicate a sulfide-based chemoautotrophic symbiosis, as shown in TEM and by testing RUBP carboxylase activity in gills (Stein et al. 1988, Galkin 1992, Desbruyères et al. 1994), and a predominantly non-photosynthetic carbon source, as shown by analysing the carbon isotope composition (Van Dover \& Fry 1989).

The situation is quite different in Ifremena nautilei where the fatty acid composition differs strongly from that previously reported for heterotrophic marine gastropods (Ackman et al. 1971, Gardner \& Riley 1972, Ackman \& Hooper 1973, Joseph 1982, Voogt 1983) but also from that of marine invertebrates associated with sulfur-oxidizing bacteria (Conway \& McDowell Capuzzo 1990, 1991, Ben-Mlih et al. 1992, Conway et al. 1992, Zhukova et al. 1992, Fullarton et al. 1995, Pranal 1995, Pranal et al. in press). I. nautilei tissues display high levels of 16 and 18 carbon MUFAs having the double bond in the $\omega 6$ or $\omega 8$ position. These unusual fatty acids are generally considered as markers for methane-utilizing bacteria (Ringelberg et al. 1989, Bowman et al. 1991, Guckert et al. 1991). Nevertheless, the absence of specific intracytoplasmic lamellae in the endobacterial cells, as seen in TEM, and the absence of methanol dehydrogenase activity in the gills (authors' unpubl. results) suggest that these markers originate not from endosymbionts but from the host metabolism and/or from the ingestion of free-living methanotrophic bacteria. The origin of $\omega 6$ MUFAs, which are also found in small amounts in Alviniconcha hessleri tissues, remains unclear (discussion below), but it seems that $16: 1 \omega 8$ and $18: 1 \omega 8$, only found in $I$. nautilei tissues, reflect a diet partially based
Table 3. Fatty acid composition of the neutral lipıds, as a percentage of total fatty acids, from the symbiotic gastropods Ifremeria nautilei and Alviniconcha hessleri collected at the hydrothermal vent site Kayo (North Fiji Basin). Values represent the mean of 2 different animals \pm SD. NL/PL: ratio of neutral lipid fatty acid/phospholipid fatty acid concentration; tr. trace

\begin{tabular}{|c|c|c|c|c|}
\hline \multirow[t]{2}{*}{ Fatty acid } & \multicolumn{2}{|c|}{ Ifremeria nautilei } & \multicolumn{2}{|c|}{ Alviniconcha hessleri } \\
\hline & Gills & Mantles & Gills & Mantles \\
\hline $14: 0$ & $0.99 \pm 0.32$ & $0.69 \pm 0.07$ & $0.59 \pm 0.05$ & $0.49 \pm 0.08$ \\
\hline $15: 0$ & $0.08 \pm 0.01$ & $-\quad-$ & $0.27 \pm 0.05$ & $\operatorname{tr}-$ \\
\hline $16: 0$ & $8.38 \pm 0.64$ & $8.16 \pm 0.44$ & $13.13 \pm 1.83$ & $8.04 \pm 3.27$ \\
\hline $17: 0$ & $0.32 \pm 0.04$ & $0.25 \pm 0.11$ & $0.31 \pm 0.10$ & $0.44 \pm 0.19$ \\
\hline $18: 0$ & $4.73 \pm 0.30$ & $5.50 \pm 0.52$ & $3.54 \pm 0.89$ & $9.32 \pm 2.58$ \\
\hline a $15: 0$ & $0.05 \pm 0.01$ & $-\quad-$ & $-\quad-$ & - \\
\hline i $17: 0$ & $-\quad-$ & $-\quad-$ & $0.08 \pm 0.01$ & $-\quad-$ \\
\hline a $17: 0$ & $0.08 \pm 0.02$ & $0.16 \pm 0.02$ & $0.08 \pm 0.03$ & $-\quad-$ \\
\hline i $19: 0$ & $-\quad-$ & $0.09 \pm 0.03$ & $0.21 \pm 0.10$ & $0.58 \pm 0.15$ \\
\hline a $19: 0$ & $0.12 \pm 0.03$ & $0.09 \pm 0.04$ & $-\quad-$ & $0.20 \pm 0.01$ \\
\hline $16: 1 \omega 5$ & $0.63 \pm 0.17$ & $0.42 \pm 0.18$ & $0.08 \pm 0.03$ & $-\quad-$ \\
\hline $16: 1 \omega 6$ & $3.76 \pm 0.48$ & $2.36 \pm 0.06$ & $0.81 \pm 0.31$ & $0.18 \pm 0.02$ \\
\hline $16: 1 \omega 7$ & $8.35 \pm 1.23$ & $5.80 \pm 0.12$ & $27.49 \pm 1.92$ & $4.31 \pm 1.41$ \\
\hline $16: 108$ & $12.29 \pm 2.07$ & $7.26 \pm 0.14$ & $-\quad-$ & $-\quad-$ \\
\hline $17: 1 \omega 6$ & $0.22 \pm 0.01$ & $-\quad-$ & $0.05 \pm 0.01$ & $-\quad-$ \\
\hline $17: 1 \omega 8$ & $0.13 \pm 0.04$ & $-\quad-$ & $0.06-$ & $-\quad-$ \\
\hline $18: 105$ & $0.30 \pm 0.07$ & $0.30 \pm 0.07$ & $0.06 \pm 0.01$ & $-\quad-$ \\
\hline $18: 1 \omega 6$ & $4.67 \pm 0.57$ & $4.94 \pm 1.99$ & $1.22 \pm 0.17$ & $0.63 \pm 0.21$ \\
\hline $18: 1 \omega 7$ & $17.75 \pm 0.56$ & $15.70 \pm 3.25$ & $11.53 \pm 0.73$ & $9.70 \pm 3.14$ \\
\hline 18:108 & $3.85 \pm 0.34$ & $2.59 \pm 0.45$ & $-\quad-$ & $-\quad-$ \\
\hline $18: 1 \omega 9$ & $3.04 \pm 0.06$ & $4.75 \pm 2.19$ & $3.24 \pm 0.36$ & $3.61 \pm 0.14$ \\
\hline 19:1 $1 \omega 8$ & $0.25 \pm 0.03$ & $0.45 \pm 0.36$ & $0.61 \pm 0.24$ & $2.04 \pm 1.24$ \\
\hline $20: 105$ & $0.16 \pm 0.03$ & $-\quad-$ & $0.08 \pm 0.03$ & $-\quad-$ \\
\hline $20: 1 \omega 7$ & $4.12 \pm 0.62$ & $3.13 \pm 0.56$ & $1.71 \pm 0.07$ & $2.97 \pm 0.97$ \\
\hline $20: 168$ & $0.50 \pm 0.08$ & $0.30 \pm 0.19$ & $-\quad-$ & $-\quad-$ \\
\hline $20: 1 \omega 9$ & $4.05 \pm 0.57$ & $6.13 \pm 1.09$ & $4.01 \pm 0.13$ & $8.17 \pm 1.77$ \\
\hline $20: 1(1) 11$ & $2.15 \pm 0.49$ & $2.13 \pm 0.54$ & $2.30 \pm 0.59$ & $3.13 \pm 0.46$ \\
\hline $18: 2 \mathrm{a}$ & $0.60 \pm 0.19$ & $0.51 \pm 0.23$ & $0.42 \pm 0.02$ & $0.21 \pm 0.12$ \\
\hline $18: 2 b$ & $0.06 \pm 0.02$ & $-\quad-$ & $0.19 \pm 0.07$ & $-\quad-$ \\
\hline $18: 2 \omega 6$ & $0.81 \pm 0.09$ & $1.39 \pm 0.71$ & $5.54 \pm 0.57$ & $7.56 \pm 2.62$ \\
\hline $18: 3 \omega 6$ & $-\quad-$ & $-\quad-$ & $-\quad-$ & $-\quad-$ \\
\hline $20: 2 \mathrm{a}$ & $0.66 \pm 0.20$ & $0.84 \pm 0.38$ & $1.39 \pm 0.08$ & $0.89 \pm 0.07$ \\
\hline $20: 2 \omega 7,15$ & $1.96 \pm 0.49$ & $1.96 \pm 0.24$ & $2.57 \pm 0.16$ & $3.66 \pm 1.83$ \\
\hline $20: 2 \omega 9,15$ & $7.78 \pm 1.60$ & $10.78 \pm 2.63$ & $6.85 \pm 0.78$ & $11.08 \pm 0.53$ \\
\hline $20: 2 \mathrm{~d}$ & $0.28 \pm 0.09$ & $0.70 \pm 0.21$ & $1.40 \pm 0.26$ & $0.77 \pm 0.11$ \\
\hline $20: 3 a$ & $1.24 \pm 0.16$ & $1.61 \pm 0.31$ & $1.24 \pm 0.34$ & $3.24 \pm 0.09$ \\
\hline $20: 4 \omega 6$ & $2.74 \pm 0.84$ & $3.48 \pm 1.32$ & $5.27 \pm 0.99$ & $7.67 \pm 0.66$ \\
\hline $20: 5 \omega 3$ & $1.16 \pm 0.15$ & $4.44 \pm 3.45$ & $1.98 \pm 0.56$ & $6.20 \pm 1.19$ \\
\hline $21: x$ & $0.49 \pm 0.08$ & $2.09 \pm 1.72$ & $1.05 \pm 0.33$ & $3.26 \pm 1.58$ \\
\hline $22: 2 a$ & $0.10 \pm 0.01$ & $0.09 \pm 0.02$ & $0.08 \pm 0.02$ & $0.46 \pm 0.03$ \\
\hline $22: 2 \omega 7,15$ & $0.43 \pm 0.03$ & $0.37 \pm 0.09$ & $0.12 \pm 0.04$ & $1.04 \pm 0.09$ \\
\hline $22: 3 a$ & $0.17 \pm 0.02$ & $0.07 \pm 0.02$ & $0.08 \pm 0.02$ & $0.18 \pm 0.02$ \\
\hline $22: 4 \omega 6$ & $0.41 \pm 0.16$ & $0.48 \pm 0.24$ & $0.31 \pm 0.06$ & $0.74 \pm 0.09$ \\
\hline $22: 5 \omega 3$ & $0.47 \pm 0.07$ & $1.38 \pm 1.12$ & $0.27 \pm 0.02$ & $0.88 \pm 0.38$ \\
\hline $\begin{array}{l}\text { Total, } \\
\text { mg g }^{-1} \text { dry } w\end{array}$ & $\begin{array}{l}37.46 \pm 8.20 \\
v t\end{array}$ & $12.67 \pm 5.74$ & $28.77 \pm 3.85$ & $7.65 \pm 1.27$ \\
\hline NL/PL & $2.91 \pm 0.37$ & $4.53 \pm 1.69$ & $2.97 \pm 0.45$ & $2.40 \pm 0.39$ \\
\hline
\end{tabular}

on exogenously synthesized organic products. These methane-utilizing bacteria markers have never before been reported in animal tissues, making their synthesis by a gastropod unlikely. They are only detected in $I$. nautilei, where they constitute more than $4 \%$ of the to- 

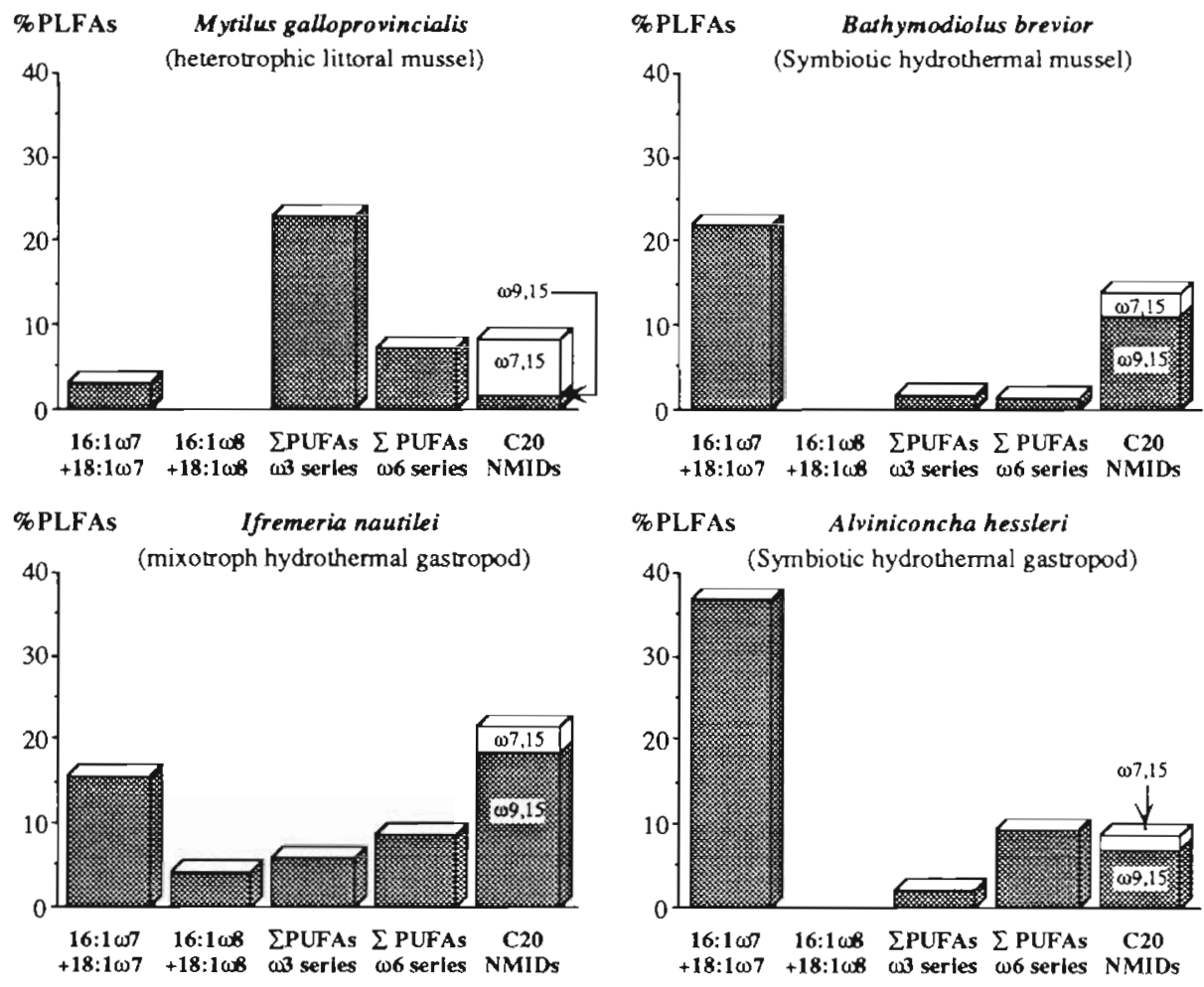

Fig. 1. Proportions of different groups of fatty acids, as percentages of total fatty acid phospholipids (PLFAs), in gills of the littoral mussel, Mytilus galloprovincialis, from Banyuls (West Mediterranean) and the hydrothermal molluscs, Bathymodiolus brevior (Pranal et al. in press), Ifremeria nautilei and Alviniconcha hessleri, from site Kayo (North Fiji Basin, West Pacific). PUFAs: polyunsaturated fatty acids; NMIDs: non-methylene-interrupted dienes

tal phospholipid fatty acids, and not in $A$. hessleri, which is believed to satisfy its requirements from the endosymbionts. Thus they probably originate from the ingestion of free-living methanotrophic bacteria. As compared to $A$. hessleri, the hypothesis of a partially heterotrophic nutrition for I nautilei is supported by: (1) the diversity and the relatively large amounts of fatty acid markers specific to various bacterial types, consisting mainly of branched and monounsaturated odd-numbered fatty acids generally related to anaerobic bacteria (Parkes \& Taylor 1983, Sargent et al. 1987, Rajendran et al. 1994), in vaccenic acid found in large amounts in aerobic micro-organisms such as sulfuroxidizing bacteria (McCaffrey et al. 1989, Conway \& McDowell Capuzzo 1990) and of $\omega 8$ series MUFAs specific to methanotrophs; (2) the homogeneous distribution of the microbial markers among organs, which could correspond to a dietary assimilation of bacterial products followed by their similar distribution between organs rather than the input of endobacterial fatty acids produced solely in the gills; and (3) the relatively high level of plant-derived fatty acids, particularly with respect to $\omega 3$ series PUFAs (Fig. 1 ).

Thus, according to the discrepancies between the nature and the distribution of the microbial markers detected in Alviniconcha hessleri and Ifremeria nautilei tissues, it seems that these 2 gastropods display distinct nutritional strategies, that for the former being mainly based on the sulfur-oxidizing symbiont production and that for the latter being probably mixotrophic, with a contribution from sulfur-oxidizing symbiont production as well as from grazed bacterial mats partially composed of free-living methane-utilizing bacteria. Our results are in agreement with in situ observations indicating a specific distribution of both gastropods on the same site, I. nautilei being not so strictly associated with the vent opening as A. hessleri (Galkin 1992, Desbruyères et al. 1994). This specific distribution could be related to the distribution of the 2 main hydrothermal energy sources for bacterial chemosyntheses, hydrogen sulfide and methane. Because of its rapid oxidation in sea water, hydrogen sulfide has a more localized distribution in the hydrothermal vent area than methane (Gal'chenko 1988). Thus, differentiation in the spatial distribution of these 2 gastropod species at any one site is probably related to their specific nutritional strategy, $A$. hessleri being closely associated with the vents in order to fuel the sulfur-oxidizing endosymbionts and $I$. nautilei being more peripherally distributed, in areas where it can both provide its 
endosymbionts with sulphides and graze bacterial mats, among which there may be methanotrophs. Nevertheless, while the trophic needs of both hydrothermal gastropods appear to be largely satisfied by the microbial products synthesized in situ, distinct nutritional strategies may allow these sympatric gastropods to avoid direct competition for their energy supply.

\section{Hydrothermal gastropod metabolism}

Compared with the symbiotic mussels collected at the same site, hydrothermal gastropods display conspicuous levels of $\omega 6$ PUFAs, on the same order of magnitude as that of a littoral heterotrophic mussel (Fig. 1). This is all the more noticeable for Alviniconcha hessleri as this gastropod is supposed to derive energy mainly from products synthesized by endosymbionts, which is confirmed by the low level of 13 PUFAs (on the same order of magnitude as that of the symbiotic mussels), particularly in gills. It is generally accepted that animals desaturate fatty acids using $\Delta 9$ desaturase, 16:0 and 18:0 being at the base of desaturations and further elongations occurring via 16:107 and 18:1 199 synthesis (Gurr \& James 1980). In contrast, plants are capable of $\Delta 12$ and $\Delta 15$ desaturations and thus constitute the main source of $\omega 3$ and $\omega 6$ PUFAs which are considered to be essential for animals (Gurr \& James 1980, Sargent et al. 1987, 1990). Nevertheless several lines of evidence indicate that some terrestrial gastropods are capable of de novo biosynthesis of linoleic acid, 18:2w6, from acetate (Van Der Horst 1973, Van Der Horst \& Oudejans 1976. Weinert et al. 1993). Although the enzyme responsible for this peculiar desaturation has not been investigated, Weinert et al. (1993) supposed that these terrestrial gastropods use the same pathway as plants and some insects, based on a $\Delta 12$ desaturation of oleic acid (Cripps et al. 1990 Borgeson et al. 1991). Compared to other marine heterotrophic invertebrates, such as bivalve molluscs or crustaceans (Ackman et al. 1971, Ackman \& Hooper 1973, Dall et al. 1991) or symbiotic mussels from the same hydrothermal site (Pranal 1995, Pranal et al. in press), A. hessleri and Ifremeria nautilei display particularly high levels of linoleic acid in their tissues. As in terrestrial gastropods, linoleic acid could originate from the host metabolism via $\Delta 9$ desaturation of stearic acid, yielding $18: 1 \omega 9$, which should be $\Delta 12$ desaturated to produce $18: 2 \omega 6$. However, considering the

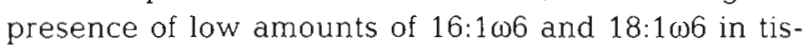
sues of both gastropods, linoleic acid could be synthezised from $\Delta 10$ desaturation of palmitic acid, yielding 16:1w6, which should then be chain-elongated to $18: 1 \omega 6$ and then $\Delta 9$-desaturated to produce $18: 2 \omega 6$. In both cases, linoleic acid could originate from the host metabolism and $\omega 6$ series PUFAs would not be considered as essential fatty acids for the hydrothermal gastropods

$\omega 6$ PUFAs may also originate from the ingestion of free-living microbes. This dietary input could be indirect via the desaturation and/or the elongation of 16:1 $\omega 6$ and 18:1 16 fatty acids assimilated by grazing methane-utilizing bacterial mats. Concerning Alviniconcha hessleri, the absence of other markers of methanotrophic bacteria (e.g. $\omega 8$ series MUFAs) makes this assumption questionable. A further possibility is a direct dietary input of $\omega 6$ PUFAs from the ingestion of benthic heterotrophic microbes such as prokaryotes which are able to synthesize their own long-chain PUFAs, as they have been previously reported to occur in deep-sea environments (Delong \& Yayanos 1986), or microeukaryotes enriched with $\omega 6$ PUFAs. Comparing the lipid composition of 2 littoral benthic invertebrates, one being a filter-feeder and the other a deposit-feeder, Bell \& Sargent (1985) observed that the deposit-feeder displayed a higher level of $\omega 6$ PUFAs than the filter-feeder. They hypothesized that this difference results from the ingestion of benthic microeukaryotes by the deposit-feeder. The same could be hypothesized in hydrothermal environments where symbiotic gastropods, which possess potentially functional organs for grazing, have a noticeably higher level of $\omega 6$ PUFAs than symbiotic mussels (Fig. 1), which are known to possess potentially functional organs for filter-feeding.

Whatever the origin of $\omega 6$ series fatty acids, hydrothermal gastropods do not appear to be depleted of $\omega 6$ series PUFAs. The level of these essential fatty acids in both deep-sea gastropods is more similar to that of heterotrophic littoral molluscs than that of symbiotic mussels collected at the same site (Fig. 1). The hydrothermal gastropods probably use an alternative pathway, based on endogenous or free-living bacterial products rather than phytoplanktonic ones, - as is supposed for most marine heterotrophic invertebrates - to maintain their specific fatty acid composition

In heterotrophic marine invertebrates, some specific fatty acids such as non-methylene-interrupted dienes (NMIDs) have been supposed to be acceptable as substitutes for 13 PUFAs (Ackman \& Hooper 1973, Klingensmith 1982). In bivalves known to feed mainly through their associated chemoautotrophic bacteria, the inverse relationship between the level of NMIDs and that of PUFAs considered to be essential reinforces this supposition (Berg et al. 1985, Zhukova et al. 1992, Fang et al. 1993). Like symbiotic bivalves, hydrothermal gastropods display substantial amounts of NMIDs These dienoic fatty acids could be related to a depletion of $\omega 3$ PUFAs. In particular, 20:2 $\omega 9,15$ is conspicuously predominant. It is of interest to note that the 
same compound is the major NMID constituent detected in all deep-sea symbiotic bivalves analysed until now methanotrophic (Fang et al. 1993) and sulfur-oxidizing mytilids (Pranal 1995, Pranal et al. in press) as well as sulfur-oxidizing vesicomyids (Pranal 1995). In contrast, NMIDs in littoral symbiotic bivalves appear to consist mainly of 22:267.15 (Berg et al. 1985, Zhukova et al. 1992, Fullarton et al. 1995, Pranal 1995). The ubiquity of 20:2w9,15 in deep-sea symbiotic molluscs strongly suggests a functional significance of this fatty acid in relation with depth. It is admitted that the chain length as well as the position of the unsaturations modify the physical properties of the fatty acids. For instance, Lomascolo et al. (1994) noted that maintenance of membrane fluidity at low temperature required the accumulation of short-chain fatty acid phospholipids and Barton \& Gunstone (1975) showed that, among several PUFA isomers, the lowest melting point was found in those which retain double bonds in the more central position. Consequently, synthesis of NMIDs by molluscs mainly feeding through endobacterial production appears to be a means to restore the depleted essential $\omega 3$ series PUFAs. More particularly, in deep-sea symbiotic species, the favoured synthesis of $20: 2 \omega 9,15$ compared to $22: 2 \omega 7,15$ probably maintains the membrane fluidity and thus could be considered an adaptation to the low temperature and the high hydrostatic pressure characterising the deep-sea environment.

\section{Energy storage}

In animals, neutral lipids are essentially used for energy storage (Gurr \& James 1980, Voogt 1983). In contrast to the phospholipid fatty acids, this lipid class does not display a specific composition but depends on the dietary inputs (Joseph 1982, Voogt 1983). Neutral lipids of both studied gastropods are characterized by an accumulation of bacteria-derivated fatty acids, especially in gills. This accumulation confirms the preponderance of the bacterial input in the nutrition of the hydrothermal gastropods. In Alviniconcha hessleri, the increase of putative microbial markers is reflected essentially by $\mathrm{C} 16: 1 \omega^{7}$ and is probably related to the assimilation of an excess of palmitoleic acid originating from the sulfur-oxidizing endobacteria. In Ifremeria nautilei, most of the MUFAs occur at high levels, particularly those of the $\omega 6, \omega 7$ and $\omega 8$ series. As also proposed for phospholipids, the diversity of the microbial markers is probably related to both carbon transfer from the endobacteria to the host and assimilation from the ingestion of free-living bacteria. Furthermore, in this species the high level of 16:1w8 in neutral lipids could indicate the inability to use this unusual fatty acid for physiological or structural purposes and thus its accumulation in neutral lipids for energetic needs. Indeed, fatty acids used as fuel do not require a peculiar configuration.

Compared to heterotrophic gastropods from littoral areas (Ackman et al. 1971, Dall et al. 1991) and to symbiotic mussels collected at the hydrothermal site (Pranal et al. in press), the hydrothermal gastropods display high concentrations of neutral lipids, particularly in gills. Despite the preferential use of glycogen by typical molluscs (Bayne et al. 1976, Livingstone \& De Zwaan 1983), the remarkable concentrations of neutral lipids found in Ifremeria nautilei and in Alviniconcha hessleri tissues suggest a preferential use of these compounds. Neutral lipids are the most condensed form of energy storage (Gabbott 1976, Gurr \& James 1980). Their accumulation in gills of both provannid gastropods, probably resulting from the degradation of bacterial phospholipids, could be considered as an adaptation to temporally unstable and spatially discontinuous environments, permitting the hydrothermal gastropods to migrate to other sites when the activity of a site is declining, as inferred from ecological observations (Denis et al. 1993).

\section{Efificacy of some fatty acids for describing the nutrition of marine invertebrates}

Comparative analysis of the fatty acid composition from various marine invertebrates shows that a diet based mainly on bacterially synthesized products is characterised by a drastic enrichment of MUFAs and a concomitant decrease of PUFAs. Particularly in the case of bacterial symbiosis, palmitoleic (16:1 107$)$ and vaccenic (18:1 $\omega 7$ ) acids appear to be ubiquitous markers for sulfur-oxidizing endobacteria. Thus, in phospholipids, their predominance compared to the other fatty acids can be directly related to the presence of sulfur-oxidizing symbionts. Furthermore, high levels of these markers in lipids other than phospholipids, particularly in neutral lipids, and in tissues other than those hostiny the endobacterid indicate an important transfer of the endobacterial products to the host. In most of the marine symbiotic invertebrates studied, the dominant role of the symbionts in the host's nutrition is closely related to the decrease of the plant-derived fatty acid level (mostly $\omega 3$ and $\omega 6$ series PUFAs). Nevertheless, fatty acid analysis of symbiotic gastropods shows that $\omega 6$ PUFAs are equivocal markers which do not allow a clear estimate of the proportion of exogenous inputs in the symbiotic invertebrate diet. Only $\omega 3$ PUFAs can unambiguously define the heterotrophic part of the diet. For symbiotic invertebrates from deepsea hydrothermal environments, in addition to the $\omega 3$ 
PUFAs which reflect the heterotrophic inputs based on processes outside the sites (i.e photosynthetic production from the photic zone), some markers such as $\omega 8$ MUFAs allow estimation of the heterotrophic inputs originating from the sites (i.e. chemosynthetic production). Marine molluscs can use a number of nutritional strategies which vary, according to the species, from entirely heterotrophic to essentially symbiotic inputs.

Acknowledgements. We are very grateful to E. Ruellan and $T$ Urabe for their invitation to the RV 'Yokosuka' cruise (1991, IFREMER-JAMSTEC). We thank the captain, crews and pilots of the 'Yokosuka' and 'Shinkaï 6500 ' as well as the scientific team for their assistance in collecting material. Anonymous referees are gratefully acknowledged for their helpful remarks. S. von Boletzky reviewed the English version. This study was supported by PNEHO grant and CNRS (LA 117).

\section{LITERATURE CITED}

Ackman RG, Hooper SN (1973) Non-methylene-interrupted fatty acids in lipids of shallow-water marine invertebrates: a comparison of two molluscs (Littorina littorea and Lunatia triseriata) with the sand shrimp (Crangon septemspinosus). Comp Biochem Physiol 46B:153-165

Ackman RG. Hooper SN, Ke PJ (1971) The distribution of saturated and isoprenoid fatty acids in the lipids of three species of molluscs, Littorina littorea, Crassostrea virgmica and Venus mercenaria. Comp Biochem Physiol 39B: 579-587

Barton PG, Gunstone FD (1975) Hydrocarbon chain packing and molecular motion in phospholipid bilayers formed from unsaturated lecithins. J Biol Chem 250:4470-4476

Bayne BL, Widdows J. Thompson RJ (1976) Physiological integrations. In: Bayne BL (ed) Marine mussels, their ecology and physiology. Cambridge University Press, London, p 261-292

Bell MV, Sargent JR (1985) Fatty acids analyses of phosphoglycerides from tissues of the clam Chlamys islandica (Muller) and the starfish Ctendiscus crispatus (Retzius) from Balsfjorden, Northern Norway. J Exp Mar Biol Ecol $87: 31-40$

Ben-Mlih F, Marty JC, Fiala-Médioni A (1992) Fatty acid composition in deep hydrothermal vent symbiotic bivalves. J Lipid Res 33:1797-1806

Berg C, Krzynowek J, Alatalo P, Wiggin K (1985) Sterol and fatty acid composition of the clam, Codakia orbicularis, with chemoautotrophic symbionts. Lipids 20:116-120

Bligh EG, Dyer WJ (1959) A rapid method of total lipid extraction and purification. Can J Biochem Physiol 37:911-917

Borgeson CE, Kurtti TJ, Munderloh UG, Blomquist GJ (1991) Insect tissues, not microorganisms, produce linoleic acid in the house cricket and the American cockroach. Experientia 47:238-241

Bouchet P. Waren A (1991) Ifremeria nautilei, nouveau gastéropode d'évents hydrothermaux, probablement associé à des bactéries symbiotiques. C R Acad Sci Paris, Sér III 312:495-501

Bowman JP, Skerratt JH, Nichols PD, Sly LI (1991) Phospholipid fatty acid and lipopolysaccharide fatty acid signature lipids in methane-utilizing bacteria. FEMS Microbiol Ecol 85:15-22

Childress JJ, Fisher C (1992) The biology of hydrothermal vent animals - physiology, biochemistry and autotrophic symbiosis. Oceanogr Mar Biol Ann Rev 30:337-441

Conway N, Howes BL, McDowell Capuzzo J, Turner RD. Cavanaugh CM (1992) Characterization and site description of Solemya borealss (Bıvalvia; Solemyidae), another bivalve-bacteria symbiosis. Mar Biol 112.601-613

Conway N, McDowell Capuzzo J (1990) The use of blochemical indicators in the study of trophic interactions in animal-bacteria symbiosis: Solemya velum, a case study. In: Barnes $M$, Gibson RN (eds) Trophic relationships in the marine environment. Proc 24th Eur Mar Biol Symp. Aberdeen University Press, Aberdeen, p 553--564

Conway N, McDowell Capuzzo J (1991) Incorporation and utilization of bacterial lipids in the Solemya velum symbiosis. Mar Biol 108:277-291

Cripps C. Borgeson C, Blomquist GJ, DeRenobales M (1990) The $\Delta 12$-desaturase from the house cricket, Acheta domesticus (Orthoptera: Gryllidae): characterization and form of the substrate. Arch Biochem Biophys 278:46-51

Dall W, Smith DM, Moore LE (1991) Biochemical composition of some prey species of Penaeus esculentus Haswell (Penaeidae: Decapoda). Aquaculture 96:151-166

Delong EF, Yayanos AA (1986) Biochemical function and ecological significance of novel bacterial lipids in deep-sea procaryotes. Appl Environ Microbiol 51:730-737

Denis F, Jollivet D, Moraga D (1993) Genetic separation of two allopatric populations of hydrothermal snails Alviniconcha spp. (Gastropoda) from two south Western Pacific back-arc basins. Biochem System Ecol 21:431-440

Desbruyeres D, Alayse-Danet AM, Onta S and the scientific parties of Biolau and Starmer cruises (1994) Deep-sea hydrothermal communities in South-western Pacific back-arc basins (the North-Fiji and Lau Basins): composition, microdistribution and food-web. In: Auzende JM, Urabe T (eds) North Fiji Basin: STARMER French-Japanese program. Mar Geol 116:227-242

Endow K, Ohta S (1989) The symbiotic relationship between bacteria and a mesogastropod snall, Alviniconcha hessleri, collected from hydrothermal vents of the Mariana Back-Arc Basin. Nihon Biseibutsu Gaikkaiho 3:73-82

Fang J, Comet PA, Brooks JM, Wade TL (1993) Nonmethylene-interrupted fatty acids of hydrocarbon seep mussels occurrence and significance. Comp Biochem Physiol 104B: 287-291

Fullarton JG, Dando PR, Sargent JR, Southward AJ, Southward EC (1995) Fatty acids of hydrothermal vent Ridgeia piscesae and inshore bivalves containing symbiotic bacteria. J Mar Biol Ass UK 75:455-468

Gabbott PA (1976) Energy metabolism. In: Bayne BL (ed) Marine mussels, their ecology and physiology. Cambridge University Press, London, p 293-337

Gal'chenko VF (1988) The role of bacterial symbionts in the diet of invertebrates from active hydrothermal regions. Okeanologiya 28:1020-1031

Galkin SV (1992) The benthic fauna of hydrothermal vents in the Manus Basin. Oceanology 32:768-774

Gardner D, Riley JP (1972) The component fatty acids of the lipids of some species of marine and freshwater molluscs. J Mar Biol Ass UK 52:827-838

Giere O, Conway NM, Gastrock G, Schmidt C (1991) Regulation of gutless annelid ecology by endosymbiotic bacteria. Mar Ecol Prog Ser 68:287-299

Guckert JB, Ringelberg DB, Withe DC. Hanson RS, Bratina BJ (1991) Membrane fatty acids as phenotypic markers in the polyphasic taxonomy of methylotrophs within the Proteobacteria. J Gen Microbiol 137:2631-2641

Guezennec J (1991) Influence of cathodic protection of mild steel on the growth of sulfate-reducing bacteria at $35^{\circ} \mathrm{C}$ in 
marine sediments. Biofouling 3:339-348

Gurr MI, James AT (eds) (1980) Lipid biochemistry, an introduction. Chapman and Hall, London

Hessler RR, Smithey WM (1983) The distribution and community structure of megafauna at the Galapagos Rift hydrothermal vents. In: Rona PA, Bostrom $\mathrm{K}$, Laubier $\mathrm{L}$, Smith KL (eds) Hydrothermal processes at the seafloor spreading center NATO Conference series 1, Plenum Press, New York, p 735-770

Ishibashi J, Grimaud D, Nojiri Y, Auzende JM, Urabe T (1994) Fluctuation of chemical composition of the phase-separated hydrothermal fluid from the North Fiji Basin Ridge. Mar Geol 116:215-226

Jollivet D and the scientific parties of Starmer cruises (1989) Premieres observations de communautés animales associées à l'hydrothermalisme arrière-arc du bassin NordFidjien. C R Acad Sci Paris, Sér III 309:301-308

Joseph JD (1982) Lipid composition of marine and estuarine invertebrates, Part II, Mollusca. Prog Lipid Res 22: $109-153$

Klingensmith JS (1982) Distribution of nonmethylene-interrupted dienoic fatty acids in polar lipids and triglycerols of selected tissues of the hardshell clam (Mercenaria mercenaria). Lipids 17:976-981

Livingstone DR, De Zwaan A (1983) Carbohydrate metabolism of gastropods. In: Wilburg KM (ed) The Mollusca, Vol 1 Academic Press, New York, p 177-230

Lomascolo A, Dubreucq E, Perrier V, Galzy P (1994) Study of lipids in Lipomyces and Waltomyces. Can J Microbiol 40: $724-729$

McCaffrey MA, Farrington JW, Repeta D (1989) Geochemical implications of the lipid composition of Thioploca spp. from the Peru upwelling region $-15^{\circ} \mathrm{S}$. Org Geochem 14:61-68

Nichols PD, Volkman JK, Everitt DA (1989) Occurrence of cis6-hexadecanoic acid and other unusual monounsaturated fatty acids in the lipids of oceanic particulate matter. Oceanol Acta 4:393-403

Okutani T, Ohta S (1988) A new gastropod mollusc associated with hydrothermal vents in the Mariana Back-Arc Basin, Western Pacific. Venus 47:1-9

Parkes RJ, Taylor $J$ (1983) The relationship between fatty acid distributions and bacterial respiratory types in contemporary marine sediments. Estuar Coast Shelf Sci 16:173-189

Pranal V (1995) Marqueurs et caractéristiques biochimiques des associations symbiotiques mollusques-bactéries chimiosynthétiques. Thesis, Pierre et Marie Curie University, Paris

Pranal V, Fiala-Médion A, Guezennec J (in press) Polar and neutral lipid characteristics in two symbiont-bearing mussels from deep-sea hydrothermal vents of the South-Western Pacific. J Mar Biol Ass UK

Rajendran N, Matsuda O. Urushıgawa Y, Simidu U (1994)

This article was submitted to the editor
Characterization of microbial community structure in the surface sediment of Osaka Bay, Japan, by phospholipid fatty acid analysis. Appl Environ Microbiol 60:248-257

Ringelberg DB, Davis JD, Smith GA, Pfiffner SM, Nichols PD, Nickels JS, Henson JT, Yates M, Kampbell DH, Read HW, Stocksdale TT, Withe DC (1989) Validation of signature polar lipid fatty acid biomarkers for alkane-utilizing bacteria in soils and subsurface aquifer materials. FEMS Microbiol Ecol 62:39-50

Sargent JR, Bell MV, Henderson RJ, Tocher DR (1990) Polyunsaturated fatty acids in the marine and terrestrial food webs. In: Mellinger J (ed) Animal nutrition and transport processes. Vol 5, Part I, Nutrition in wild and domestic animals. Karger, Basel, p 11-23

Sargent JR, Parkes RJ, Mueller-Harvey I Henderson RJ (1987) Lipid biomarkers in marine ecology. In: Sleigh MA (ed) Microbes in the sea. E Horwood Ltd, London, $p$ $119-138$

Stein JL, Craig C, Hessler RR, Ohta S, Vetter RD, Childress JJ, Felbeck $H$ (1988) Chemoautotrophic symbiosis in a hydrothermal vent gastropod. Biol Bull 174:373-378

Tunnicliffe V (1991) The biology of hydrothermal vents. Oceanog Mar Biol Ann Rev 29:319-407

Van Der Horst DJ (1973) Biosynthesis of saturated and unsaturated fatty acids in the pulmonate land snail Cepaea nemoralis (L.). Comp Biochem Physiol 468:551-560

Van Der Horst DJ, Oudejans RCHM (1976) Fate of dietary linoleic and linolenic acids in the land snail Cepaea nemoralis (L.). Comp Biochem Physiol 55B:16?-170

Van Dover CL, Fry B (1989) Stable isotopic compositions of hydrothermal vent organisms. Mar Biol 102:257-263

Von Cosel R, Métivier B, Hashimoto J (1994) Three new Bathymodiolus (Bivalvia: Mytilidae) from hydrothermal vents in the Lau Basin and the North Fiji Basin. Western Pacific, and the Snake Pit area, Mid-Atlantic Ridge. Veliger 37:374-392

Voogt PA (1983) Lipids: their distribution and metabolism. In: Wilburg K (ed) The Mollusca, Vol 1. Academic Press, New York, p 329-371

Waren A, Bouchet P (1993) New gastropods from hydrothermal vents and hydrocarbon seeps in the Caribbean, the Atlantic, and the Pacific. Zool Scripta 22:1-90

Weinert J, Blomquist GJ, Borgeson CE (1993) De novo biosynthesis of linoleic acid in two non-insect invertebrates: the land slug and the garden snail. Experientia 49 : 919-921

White DC, Bobbie RJ, Morrison SJ, Osternof DK, Taylor CW, Meeter DH (1977) Determination of microbial activity of estuarine detritus by relative rates of lipid biosynthesis. Limnol Oceanogr 22(6):1089-1099

Zhukova NV, Kharlamenko VI, Svetashev VI, Rodionov IA (1992) Fatty acids as markers of bacterial symbionts of marine bivalve molluscs. J Exp Mar Biol Ecol 162:253-263

Manuscript first received: February 12, 1996

Revised version accepted: June 12, 1996 